\title{
DEVOICING IN POST-VOCALIC CANADIAN-FRENCH OBSTRUANTS
}

\author{
Danièle Archambault \\ Blagovesta Maneva \\ Laboratoire de Phonétique, Université de Montréal \\ C.P.6128, Succ. Centre-Ville, Montréal (Qué.) \\ Canada, H3C 3J7
}

\begin{abstract}
In Canadian French, besides periodic phonation, other cues can be associated with the voiced-voiceless distinction due to the application of phonological rules. These cues, mainly duration and vowel quality, may be present in the consonant itself (voiced consonants are shorter than their voiceless counterparts) and in the preceding vowels (duration and vowel quality). The cues are related to the application of an allophonic rule and the presence in the phoneme inventory of intrinsically long and short vowels. The tendancy towards devoicing of some portion of a normally voiced consonant in postvocalic word-final positions is found in many languages. This study investigates the patterns of devoicing in post-vocalic obtruants in Canadian French and attempts to verify the following functional hypothesis: a consonant will be more resistant to devoicing (absence of periodic structure) if no (or few) other cues of the voiced-voiceless distinction can be found either in the consonant itself or in the preceding vowel. The data will serve as a reference for current studies on patients with apraxia of speech.
\end{abstract}

\section{INTRODUCTION}

The tendancy towards devoicing of some portion of a normally voiced consonant in postvocalic word-final positions is found in many languages (Flege and Brown, 1982 [2] and Kluender et all., 1988 [3]). A devoicing tendancy is also one of the major caracteristics of Broca's aphasia and verbal apraxia. In normal French speech, there is also a tendancy towards devoicing of some portion of a normally voiced consonant in postvocalic word-final positions (Wajskop and Sweerts, 1973 [7]). Unfortunately, comparisons between "normal " and "pathological" devoicing are difficult because of a lack of comparable systematic study describing "normal devoicing". This study investigates the patterns of devoicing in postvocalic obtruants in Canadian French. The data will serve as a reference for current studies [1] on patients with apraxia of speech.

\section{METHODOLOGY}

\subsection{Data}

We systematically examined voiced and voiceless obstruants (plosives and fricatives) in different phonemic environments. The corpus was designed to test the following hypothesis: a consonant will be more resistant to devoicing (absence of periodic structure) if no (or few) other cues of the voiced-voiceless distinction can be found either in the consonant itself or in the preceding vowel. The cues are mainly duration and vowel quality. They can be found in the consonant itself (voiced consonants are usually shorter than their unvoiced counterparts) and in the preceding vowel. In the vowels the cues are related, first, to the quality of the vowel. The cues represent allophonic variation: high vowel allophones are not the same when followed by voiced fricatives (allophones are tense vowels; e.g. Lise [li:z]) as when followed by voiceless fricatives (allophones are lax vowels; e.g. Lys [1Is]). Second, they are related to duration: (vowels are usually longer before voiced consonants). However in this variety of French, the phoneme inventory shows, as in English and other languages, a series of intrinsically long (e.g. côte [ko:t]) and short vowels (e.g. cote $/ \mathrm{kOt}]$ ). In the context of intrinsically long vowels, the difference of duration would be less important. Therefore the corpus was designed to include words showing a variety of cues to the voiced/voiceless distinction.

\begin{tabular}{|c|c|c|c|}
\hline CONTEXT & $\begin{array}{c}\text { unvoiced } \\
(\mathrm{n})\end{array}$ & $\begin{array}{c}\text { voiced } \\
(n)\end{array}$ & total \\
\hline $\mathrm{v}[+$ high $] /$ fric & lys (14) & Lise (14) & 28 \\
\hline $\mathrm{v}[+$ high / _ plos & motte (5) & mode (5) & 10 \\
\hline SUBTOTAL & 19 & 19 & 38 \\
\hline $\begin{array}{l}\mathrm{v}[\text { [-long] / } / \text { fric } \\
\text { [-high] }\end{array}$ & bref (10) & brève (10) & 20 \\
\hline $\begin{array}{l}\mathrm{v}[\text {-long] / } \\
{[\text {-high] }}\end{array}$ & vaque (6) & vague (6) & 12 \\
\hline SUBTOTAL & 16 & 16 & 32 \\
\hline $\mathrm{v}$ [+long] /_fric & lâche(10) & l'âge (11) & 21 \\
\hline $\mathrm{v}[+$ long $] /-$ plos & monte (5) & monde (4) & 9 \\
\hline SUBTOTAL & 15 & 15 & 30 \\
\hline TOTAL & 50 & 50 & 100 \\
\hline
\end{tabular}

Figure 1: Corpus of 100 words

A list of 100 words in carrier sentences were submitted to ten speakers (five males, five females), all university students between the age of 20 and 30 years old. The words were selected according to the following criteria: voiced and unvoiced targets (all the obstruants are included), postvocalic word-final consonants, minimal pairs and non minimal pairs, different sets of preceding vowels. The speakers were asked to read all the sentences at normal speed. 
The audio recording were conducted in a soundproof room using a Nagra tape recorder.

\section{RESULTS.}

\subsection{Duration as Voicing Cue in Postvocalic French Obstruants}

The acoustic analysis was carried out using digital spectrograph software (Visu PC) focusing on the energy in the low frequencies. A total of 100 words was analyzed. Various measurements included duration of the syllable (usually $\mathrm{CVC}$ ), duration of the rime (VC), total duration of the vowel, duration of voicing in the vowel, total duration of the final consonant, duration of voicing in the final consonant. From these measurements, different ratios were computed.

The duration measures indicate a strong link between the voiced/voiceless nature of a consonant, its duration and the duration of the preceding vowel.

All vowels are longer when followed by a voiced consonant than when followed by an unvoiced one (Average real time: $48.8 \mathrm{~ms}$ to $171.7 \mathrm{~ms}$ longer; $18.4 \%$ to $117.8 \%$ ). However, the strength of this correlation depends on the nature of the vowel and the consonant. When comparing the durations of vowels followed by voiced consonants to the duration of those followed by unvoiced ones, we find that intrinsically long vowels are on average $18.4 \%$ longer before voiced plosives than before unvoiced ones and 20\% longer before voiced fricatives than before unvoiced ones; short vowels are $44.4 \%$ longer before voiced plosives if they are not also high vowels and $51.4 \%$ longer if they are; the same vowels are $117.8 \%$ and $80.6 \%$ longer respectively before voiced fricatives. If short high vowels are so much longer before voiced consonants than before unvoiced consonants, it is because this specific category of vowels is in fact quite short in the context of unvoiced consonants, especially with fricatives. Furthermore, high vowel deletion is very common in this segmental context when the syllable is not stressed. However, even if their percentage of lenghtening is greather than the other intrinsically short ones, actual real time durations of high vowels always remain shorter. Also, although short vowels become phonetically long in certain context, their actual real time duration never get as important as these of the intrinsically long vowels.

Voiced consonants are also shorter than their unvoiced counterparts ( 35.7 to $49.5 \%$ shorter) but not in the same proportion as the vowels. The range of average duration for the voiced consonants is also quite small (125 ms to 142.7 $\mathrm{ms}$ ) and might be related to a threshold of incompressibillity. These variations of duration are important to consider because they were shown to be perceptually important as voicing cues in our previous study on apraxia of speech [1]. Furthermore, as was mentioned before in various studies (Archambault and Bergeron 1990 [1], Santerre, 1991 [5] et Ouellet, 1992 [4]), vowel and consonant duration inside the rime part of the syllable do not vary independently which means that a short vowel duration is usually associated with a long consonant duration and vice versa. Therefore, the duration cues for voicing can be found in the vowel and in the consonant as well.

\subsection{Devoicing: general tendancy}

A total of 500 voiced consonants was examined for this study. The results (Fig. 2) show that only 200 consonants show absolutely no devoicing. Of the 300 remaining ones, 31 are totally devoiced (almost half of them (13) by the same speaker), and 213 show a devoicing for at least $50 \%$ of their duration. This means that $60 \%$ of all consonants show some devoicing and that $81.3 \%$ of these consonants are devoiced on more than $50 \%$ of their duration.

\begin{tabular}{|c|c|c|c|c|}
\cline { 2 - 5 } \multicolumn{1}{c|}{} & None & \multicolumn{2}{c|}{ Partial } & Full \\
\hline Speaker & $\mathbf{0 \%}$ & $\mathbf{1 \% - 5 0 \%}$ & $\mathbf{5 1 \% - 9 9 \%}$ & $\mathbf{1 0 0 \%}$ \\
\hline \hline M5 & 22 & 2 & 21 & 5 \\
\hline M3 & 18 & 7 & 25 & 0 \\
\hline F1 & 27 & 7 & 15 & 1 \\
\hline F4 & 29 & 5 & 16 & 0 \\
\hline M1 & 17 & 11 & 22 & 0 \\
\hline F5 & 12 & 4 & 21 & 13 \\
\hline F3 & 25 & 1 & 23 & 1 \\
\hline F2 & 12 & 6 & 30 & 2 \\
\hline M4 & 13 & 7 & 22 & 8 \\
\hline M2 & 25 & 6 & 18 & 1 \\
\hline \hline Total & 200 & 56 & 213 & 31 \\
\hline
\end{tabular}

Figure 2: Number of consonants exhibiting different degrees of devoicing for each speaker

\subsection{Devoicing and consonant type}

Each consonant type in the study showed a different amount of devoicing. Figure 3 shows for each consonant and each speaker the average devoicing (average percentage devoicing duration). Fricatives show a bigger proportion of devoicing time than plosives (9\% and 56\%). So plosives are quite resistant to devoicing. Some speakers tend to devoice more than others. In this category, three out of ten speakers don't devoice at all. Fricatives, however, tend to be devoiced by all speakers but not to the same extent. Average devoicing goes from $34 \%$ (Speaker F4) to 74\% (Speaker F5). Also, the consonant $/ \mathrm{Z} /$ tends to show a bigger proportion of devoicing $(63 \%)$ than the consonant $/ \mathrm{z} /(56 \%)$ and $/ \mathrm{z} /$ more than $/ \mathrm{v} /(44 \%)$.

Although it is true that plosives tend to be on average shorter than the fricatives, it is not possible to establish a correlation between the duration of the consonant and the percentage of devoicing.

There is, as we mentioned above, a reorganization of vowel and consonant duration inside the rime of the syllable. The consonant and vowel durations do not vary independently which means that a short vowel duration is usually associated with a long consonant duration and vice versa. Even if one may view this reorganization as a tendancy to equalize the rime duration, this tendancy is partially blocked by the 
seeming incompressibillity of consonant durations. Consonants do not lenghten as much as vowels. However, this duration reorganizations of the rime creates a change in the ratio Vowel/Rime (Fig.4). This ratio increases in voiced rimes $(71 \%$ in the context of voiced fricatives and $65 \%$ in the context of voiced plosives) and decreases in unvoiced rimes (46\% for fricatives and $44 \%$ for plosives). Partial or full devoicing of the consonant does not affect this ratio.

\subsection{Devoicing and vocalic classes}

We wanted to verify the functionalist hypothesis that a consonant would be more resistant to devoicing if no (or few) other cues of the voiced-voiceless distinction can be found either in the consonant itself or in the preceding vowel. This means that we would find more devoicing in consonants following short high vowels because there are cues in the duration and the quality of the vowels (tense allophones before voiced consonants and lax allophones before unvoiced consonants). We would expect also less devoicing in consonants following intrinsically long vowels, which show the same vowel quality and very little duration difference in voiced and unvoiced contexts. This hypothesis was not verified (Fig.5). Fricatives show an average of $57 \%$ devoicing after intrinsically long vowels and of $59 \%$ after high short vowels. They show an average of only $39 \%$ devoicing after short nonhigh vowels, but this can be explained in part by the frequent occurrence of the consonant $/ \mathrm{v} /$ in that context, which is more resistant to devoicing as we saw earlier.

\section{CONCLUSION}

All speakers show some degree of devoicing but the tendancy towards devoicing varies greatly and is not categorial in postvocalic position. Some speakers show a greater tendancy towards devoicing then others. This would be important to keep in mind when using these data as a reference for our studies on patients with apraxia of speech. Also, the study would benefit from an increase in data especially to get a wider spread of age and a greater variey of socioeconomic backgrounds.

Some consonants are more susceptible to devoicing than others. For all speakers, fricatives are more susceptible to devoicing than plosives and this is true for all speakers. The consonant $/ \mathrm{v} /$, although it also gets devoiced, is more resistant to devoicing than the other fricatives. This could be linked to the lesser noise component found in this consonant due to its articulatory nature (labio-dental do not produce a high level of noise friction) than to the one found in the other fricatives. Therefore, it creates less pressure on the vocal cords allowing them to vibrate more efficiently.

Finally, although the different cues (duration and vowel quality) associated with the voiced/voiceless distinction were found to be perceptually important in a previous study [1], we found that it was not possible to correlate the presence of these cues with the quantity of devoicing. in a consonant. Our functionalist hypothesis was not verified.

\section{REFERENCES}

1. Archambault, D. \& M. Bergeron (1990), "Is Devoicing a Phonetic or Phonetic Problem? A Case Study of a Patient with Apraxia of Speech", in Journal of Neurolinguistics, vol.5, no.2-3, pp.265-284.

2. Flege, J. E. \& W. S. Brown Jr. (1982), "The voicing contrast between English $/ \mathrm{p} /$ and $/ \mathrm{b} /$ as a function of stress and position-in-utterance", Journal of Phonetics 10, pp. 335-345.

3..Kluender, K., R. L. Diehl \& B. A. Wright (1988), "Vowellength differences before voiced and voiceless consonants: an auditory explanation", Journal of Phonetics 16, pp. 153169.

4. Ouellet, M. (1992), Systématiques des durées segmentales dans les syllabes en français de France et du Québec. Ph.D. Dissertation, University of Montréal.

5. Santerre, L. (1991), "Incidences du trait phonologique de durée vocalique sur la prosodie du français québécois", Proceedings of the XIIth International Congress of Phonetic Sciences, vol.4, pp. 254-257.

6. Stevens, K.N. \& D. H. Klatt (1974), "Role of formant transitions in the voiced-voiceless distinction for stops", Journal of the Acoustical Society of America 64, pp. 13581368

7..Wajskop, M. \& J. Sweerts (1973), "Voicing cues in oral stop consonants", Journal of Phonetics 1, pp. 121-130. 


\begin{tabular}{|c|c|c|c|c|c|c|c|c|}
\hline Speaker & $/ \mathbf{b} /$ & $/ \mathrm{d} /$ & $\lg /$ & $/ \mathrm{v} /$ & $|\mathrm{z}|$ & IZI & $\begin{array}{c}\text { Av. } \\
\text { plosives }\end{array}$ & $\begin{array}{c}\text { Av } \\
\text { fricatives }\end{array}$ \\
\hline F5 & $33 \%$ & $15 \%$ & $21 \%$ & $53 \%$ & $79 \%$ & $90 \%$ & $23 \%$ & $74 \%$ \\
\hline $\mathrm{F} 2$ & $3 \%$ & $4 \%$ & $26 \%$ & $54 \%$ & $81 \%$ & $83 \%$ & $11 \%$ & $73 \%$ \\
\hline M4 & $16 \%$ & $14 \%$ & $7 \%$ & $75 \%$ & $59 \%$ & $76 \%$ & $12 \%$ & $70 \%$ \\
\hline M1 & $0 \%$ & $2 \%$ & $0 \%$ & $60 \%$ & $47 \%$ & $78 \%$ & $1 \%$ & $62 \%$ \\
\hline M5 & $9 \%$ & $0 \%$ & $0 \%$ & $57 \%$ & $50 \%$ & $57 \%$ & $3 \%$ & $55 \%$ \\
\hline F3 & $0 \%$ & $0 \%$ & $0 \%$ & $42 \%$ & $58 \%$ & $46 \%$ & $0 \%$ & $49 \%$ \\
\hline M3 & $0 \%$ & $7 \%$ & $35 \%$ & $19 \%$ & $65 \%$ & $60 \%$ & $14 \%$ & $48 \%$ \\
\hline $\mathrm{F} 1$ & $0 \%$ & $0 \%$ & $0 \%$ & $42 \%$ & $41 \%$ & $37 \%$ & $0 \%$ & $40 \%$ \\
\hline M2 & $8 \%$ & $4 \%$ & $0 \%$ & $32 \%$ & $28 \%$ & $53 \%$ & $4 \%$ & $38 \%$ \\
\hline $\mathrm{F} 4$ & $0 \%$ & $0 \%$ & $0 \%$ & $2 \%$ & $53 \%$ & $47 \%$ & $0 \%$ & $34 \%$ \\
\hline Average & $7 \%$ & $5 \%$ & $9 \%$ & $44 \%$ & $56 \%$ & $63 \%$ & $9 \%$ & $56 \%$ \\
\hline
\end{tabular}

Figure 3: Percentage of devoicing for each speaker

\begin{tabular}{|c|c|c|c|c|c|c|}
\hline \multirow[b]{3}{*}{ Speaker } & \multicolumn{3}{|c|}{ Plosives } & \multicolumn{3}{|c|}{ Fricatives } \\
\hline & \multicolumn{2}{|c|}{ Lenis } & \multirow{2}{*}{$\begin{array}{c}\text { Fortis } \\
\text { V/Rime } \\
\end{array}$} & \multicolumn{2}{|c|}{ Lenis } & \multirow{2}{*}{$\begin{array}{c}\text { Fortis } \\
\text { V/Rime } \\
\end{array}$} \\
\hline & Devoicing & V/Rime & & Devoicing & V/Rime & \\
\hline F5 & $51 \%$ & $63 \%$ & $48 \%$ & $77 \%$ & $67 \%$ & $56 \%$ \\
\hline $\mathrm{F} 2$ & $8 \%$ & $73 \%$ & $55 \%$ & $75 \%$ & $75 \%$ & $52 \%$ \\
\hline M4 & $13 \%$ & $50 \%$ & $35 \%$ & $70 \%$ & $72 \%$ & $39 \%$ \\
\hline M1 & $1 \%$ & $66 \%$ & $36 \%$ & $64 \%$ & $70 \%$ & $43 \%$ \\
\hline M5 & $2 \%$ & $60 \%$ & $46 \%$ & $55 \%$ & $76 \%$ & $48 \%$ \\
\hline M3 & $11 \%$ & $66 \%$ & $44 \%$ & $51 \%$ & $73 \%$ & $43 \%$ \\
\hline F3 & $0 \%$ & $70 \%$ & $42 \%$ & $49 \%$ & $71 \%$ & $49 \%$ \\
\hline M2 & $4 \%$ & $59 \%$ & $42 \%$ & $40 \%$ & $66 \%$ & $41 \%$ \\
\hline F1 & $0 \%$ & $69 \%$ & $45 \%$ & $40 \%$ & $70 \%$ & $44 \%$ \\
\hline $\mathrm{F} 4$ & $0 \%$ & $76 \%$ & $51 \%$ & $37 \%$ & $71 \%$ & $48 \%$ \\
\hline Average & $9 \%$ & $65 \%$ & $44 \%$ & $56 \%$ & $71 \%$ & $46 \%$ \\
\hline
\end{tabular}

Figure 4: Ratio Vowel/Rime and percentage of consonant devoicing for each speaker

\begin{tabular}{|c|c|c|c|c|c|c|c|c|}
\cline { 2 - 9 } \multicolumn{1}{c|}{} & \multicolumn{3}{c|}{ Plosives } & \multicolumn{3}{c|}{ Fricatives (lenis) } \\
\cline { 2 - 9 } \multicolumn{1}{c|}{} & V+short & V+short & V+short & V+long & V+short & V+short & V+short & V+long \\
\hline Speaker & V+high & V-high & V-low & & V+high & V-high & V-low & \\
\hline \hline F5 & $39 \%$ & $3 \%$ & $51 \%$ & $14 \%$ & $74 \%$ & $41 \%$ & $89 \%$ & $83 \%$ \\
\hline F2 & $14 \%$ & $11 \%$ & $16 \%$ & $7 \%$ & $82 \%$ & $38 \%$ & $69 \%$ & $79 \%$ \\
\hline M4 & $23 \%$ & $0 \%$ & $9 \%$ & $16 \%$ & $66 \%$ & $80 \%$ & $73 \%$ & $71 \%$ \\
\hline M1 & $0 \%$ & $5 \%$ & $13 \%$ & $4 \%$ & $68 \%$ & $45 \%$ & $71 \%$ & $58 \%$ \\
\hline M5 & $16 \%$ & $6 \%$ & $22 \%$ & $9 \%$ & $61 \%$ & $73 \%$ & $54 \%$ & $44 \%$ \\
\hline M3 & $10 \%$ & $9 \%$ & $41 \%$ & $9 \%$ & $44 \%$ & $33 \%$ & $51 \%$ & $66 \%$ \\
\hline F3 & $5 \%$ & $0 \%$ & $0 \%$ & $0 \%$ & $66 \%$ & $25 \%$ & $32 \%$ & $44 \%$ \\
\hline M2 & $8 \%$ & $13 \%$ & $4 \%$ & $8 \%$ & $35 \%$ & $44 \%$ & $55 \%$ & $33 \%$ \\
\hline F1 & $7 \%$ & $0 \%$ & $3 \%$ & $0 \%$ & $44 \%$ & $12 \%$ & $33 \%$ & $45 \%$ \\
\hline F4 & $0 \%$ & $0 \%$ & $0 \%$ & $0 \%$ & $48 \%$ & $0 \%$ & $24 \%$ & $42 \%$ \\
\hline \hline Average & $12 \%$ & $5 \%$ & $16 \%$ & $7 \%$ & $59 \%$ & $39 \%$ & $55 \%$ & $57 \%$ \\
\hline
\end{tabular}

Figure 5: Degree of consonant devoicing in relation with vocalic class for each speaker 